\title{
Gender in Education Settings: Case Study of English Primary School Textbooks in Armenia
}

\author{
Ani Kojoyan, Inna Aghakhanyan \\ Yerevan State University
}

\begin{abstract}
School textbooks do not only transmit information and knowledge, but also educate and teach students certain social roles, norms, standards, behaviors, attitudes and manners. From this perspective, it becomes important to analyze those textbooks and observe what norms are standardized, what behaviors are encouraged and what stereotypes are circulated and normalized through them. The present article focuses on the analysis of gender in terms of gender roles and stereotypes in English textbooks of primary schools in Armenia.
\end{abstract}

Key words: gender, gender roles, gender stereotypes, EFL/ English textbook.

\section{Introduction}

During the recent decades, there has been a rising interest in gender and language studies and their interrelation as well as their presentation and formation in and via social institutions, including education.

Language not only reflects but also creates a social reality (Litosseliti 2013). This means that language itself, and the way we use it, influences our selfperception, our gender formation and communication with others. Language and gender are social constructions (Ibid., Crawford 1995). Studies reveal that second/ foreign language acquisition is also a social phenomenon directly influencing a learner's gender identity and communication (Litosseliti 2013, Bandura 1963).

Education, as one of the most powerful and dynamic social institutions, also plays an important role in the formation of a learner's personality and gender (DeFrancisco 2013; DeFrancisco 2007). This is realized via teacher- 
student and student-student interactions and also through educational materials, including textbooks. From this perspective, it becomes interesting and important to study EFL/ English textbooks.

The present article is devoted to the study of gender in English primary school textbooks in Armenia. Particularly, we aim at studying what female and male characteristics are portrayed and how they are presented, what social roles are given to them, how femininity and masculinity are presented, and whether these characters and social roles follow stereotypical patterns or more progressive ones. Within the framework of our methodology we have applied post-structuralism which enables us to study the object of the work in a particular context. As a research method we have applied critical discourse analysis. For our analyses we have English public school textbooks compiled by Armenian authors G. Gasparyan (2018, 2019) and M. Apresyan (2016).

\section{Language and Gender Interaction}

Language is not only a means for conveying certain messages and holding communication between each other but, being a social construction, it also turns into a powerful means for reflecting and constructing the social reality and world; it both reflects and creates how we see the world and how we see the world also contains our assumptions and stereotypes, including gender ones, about the world, us and others (Litosseliti 2013).

A number of current researches claim that people become gendered through the language they use and also through the gendered discourses they practice or participate in (Ibid. DeFrancisco 2007). It is important to note that not only men but also women may initiate gendered and sexist discourses in various situations and environments. But it is not only human beings who articulate or participate in such practices. These gendered discourses and sexist language are rooted, fixed and circulated in a number of settings, including media (advertisements, magazines, TV and talk shows, soap operas, etc.) and educational materials, such as textbooks. 


\section{Policy Framework and Gendered Educational Materials}

Since the 1970s a number of researches have been carried out worldwide to study the gender character of educational materials, particularly school textbooks (Litosseliti 2013). The research findings have claimed that those materials are heavily gendered in their character. The recent local researches (Kojoyan 2015, Tsaturyan 2013) have shown that textbooks in Armenia are also gendered. However, it is not always that textbook compilers, publishers, editors and teachers recognize this or give any importance to this issue.

For the last decades, a number of countries, including Armenia, have joined and signed (and/ or ratified) a number of international agreements, declarations and conventions and developed local strategies and polices, among them UN Convention on the Elimination of All Forms of Discrimination against Women (Armenia ratified it in 1993), CoE Convention on Preventing and Combating Violence against Women and Domestic Violence (Armenia signed it in 2018), RA Law on Ensuring Equal Rights and Equal Opportunities to Women and Men (adopted 2013), RA 2019-2023 Gender Policy Strategy and Its Action Plan (adopted in 2019). Within the framework of these regulations and documents, Armenia has taken over responsibilities to promote equal rights and opportunities as well as equal participation and expansion of women and men in various spheres and fight and eliminate gender inequality and discrimination in various settings, including in the educational ones. Currently, the RA Ministry of Education, Science, Culture and Sport has initiated a revision and development of state education and curricula standards, in which gender mainstreaming in education is an essential component to be taken into account and incorporated.

It is also important to note that during their psychological, physical, moral and intellectual development, school students spend most of their daily time at school or alternatively out of school while still being engaged with school and home-task activities. Thus, inevitably those interactions at school as well as those with educational materials enormously affect the formation of students' gender as well as their general perception of gender roles in society. 
For our analyses we have taken third- and fourth-grade English public school textbooks compiled by Armenian authors G. Gasparyan and M. Apresyan.

Our analyses have shown that the selected English school textbooks are predominantly male-centered, i.e. their texts, exercises and tasks as well as images over-represent male characters, the choice of profession, social roles as well as females and males' characteristics are conditioned by gender and presented through this lens.

Gender Roles and Stereotypes: Case Study of the $3^{\text {rd }}$-grade English Public School Textbook in Armenia

When students learn letters in the third grade, the basic examples are provided as follows:

Ann and the cat, Dad and the car, it is Dad's hammer, it is Dad's car, Ann has not a hammer, Ann has an iron. Dad has a Jeep. Mother has a big jug. Ann has a cat, it is a small cat, Bob has a dog, it is a big dog, Bob has a big dog, Ann has a small cat, Bob's Dad has a car, Ann's mother does not have a car.

(Gasparyan 2018:65, 68, 95).

On page 58 (Gasparyan 2018), there is a text where the father is presented the one who has a car, whereas the mother does not. There is a post-text exercise that fixes the knowledge gained through the text. The "True or False" exercise requires the students to answer the questions according to the provided information in the text. Those sentences read as follows: "Bob's dad has a car." and this expects and accepts the answer "Yes", and in another case, "Ann's mother has a car." requires an answer "No". This text emphasizes traditional gender roles in society and the following exercise circulates and reinforces the stereotype that driving, or owning big animals, or working with tools like a hammer, is a typical male characteristic, whereas female characters are 
presented as ones to iron and possess kitchen/ household items, own small animals and not to own a car.

In another unit, when children are introduced letter "Pp", below some words are presented starting with this letter. One of them is "pupil". And though the word "pupil" has no gender marker, a male character is portrayed next to it (Ibid. 62).

Exercises systematically present male characters, and these male characters are over-represented throughout the whole textbook. For example, in Unit 13B Personal and possessive pronouns singular are introduced. After the theoretical material is presented, there are some tasks to complete:

Exercise 9 (p. 106): Choose the correct answer:

- What is your name?

- Is your name Bob? a) she b) he c) it

- Are you John? Yes, ... a) he is b) it is c) she is

- Is his name Adam? Yes, ... .a) he is b) it is c) she is

Below we present two other randomly selected exercises, which also show the same male-centered pattern, where in the first exercise, 4 out 9 characters are males and only 1 female character is introduced, and in the second exercise, 6 out of 13 are again male and no female character is presented.

Exercise 2: Make the sentences interrogative and negative.

1. Every day I get up at 8 o'clock. 2. Bob does his morning exercises. 3. You wash your hands and face. 4. After breakfast he goes to school. 5. She does her lessons. 6. We play computer games. 7. They watch TV in the evening. 8. Tom goes to bed at 9 o'clock. 9. He comes home at 5 o'clock.

(Gasparyan 2018:152) 
Exercise 1: Fill in the missing prepositions.

1. He goes ... work every morning. 2. There is a vase ... the table.3. Jim lives ... London. 4. He does not work ... Saturday and Sunday. 5. He has many friends ... school. 6. There are many flowers ... the tree. 7. I go home ... school. 8. There is a picture ... the wall. 9. His father works ... office. 10. He usually watches $T V$... the evening. 11. I go to school ...8 o'clock in the morning. 12. There is a garden ........ our house. 13. ... breakfast I go to school.

(Gasparyan 2018:168)

We notice that professions are also divided according to traditional and stereotypical gender lens in the textbook.

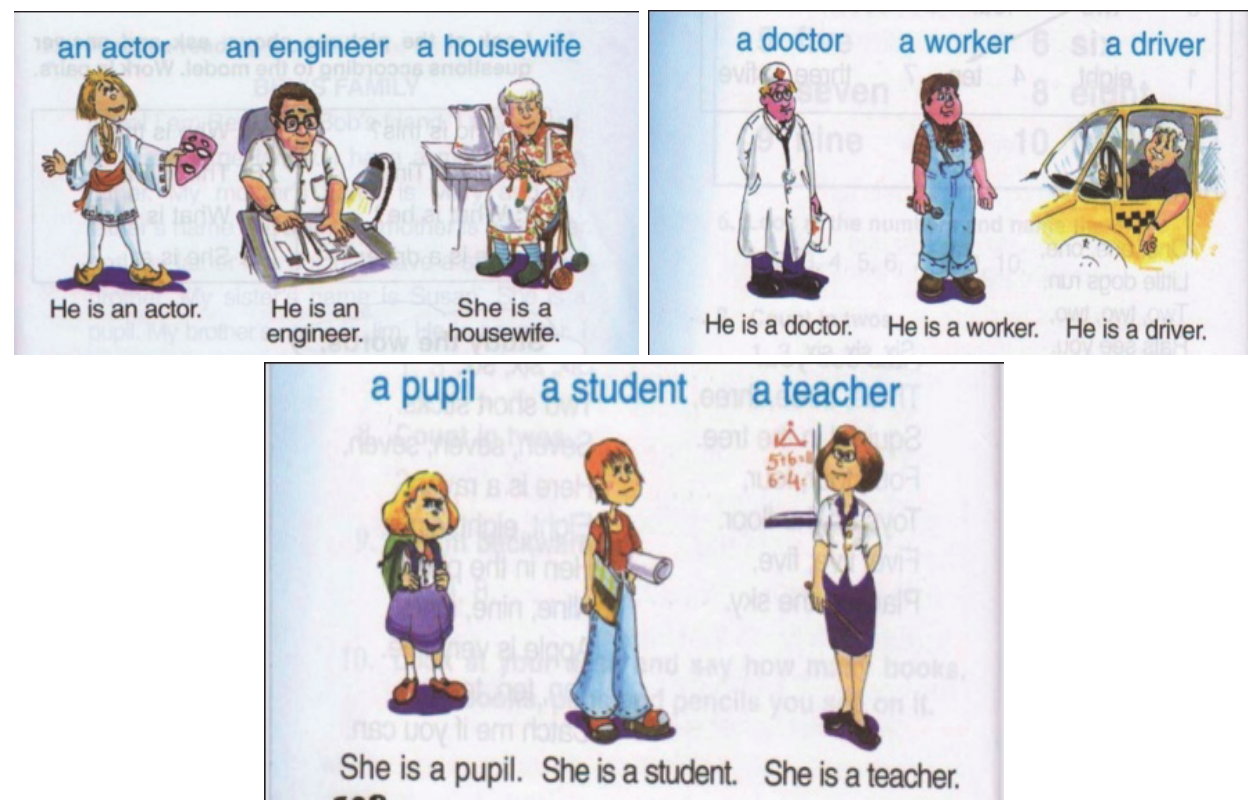

Pictures taken from English textbook, $3^{\text {rd }}$ grade (Gasparyan 2018:116) 
Doctors, workers, drivers, actors, and engineers are portrayed as male characters, whereas housewives and teachers as female (Gasparyan 2018:116117).

In the text Ben's family, Ben presents his family members according to their professions:

My mother is a teacher. My father is a doctor. My brother is an actor. My grandfather is a driver. My grandmother is a housewife".

(Gasparyan 2018:119)

In the next text, Jim Brown, Jim's parents are introduced in the following way:

Jim's father, Mr. Brown works at a big office. He goes to work every morning and comes back at 6 o'clock, Jim's mother, Mrs. Brown is a housewife. She works at home. She cleans the house and makes breakfast, dinner, and supper.

(Gasparyan 2018:154)

This traditional and stereotypical division of gender roles and professions can be observed throughout the whole textbook systematically.

Another stereotypical approach of men being active and women being passive can be observed in one of the texts of the textbook. The text Jim's house contains the following passage:

On Saturday and on Sunday Mr. Brown likes to work in the garden. Mrs. Brown doesn't like to work in the garden. She likes to sit under a tree and read a book.

(Gasparyan 2018:165) 
Gender Roles and Stereotypes: Case Study of the $4^{\text {th }}$-grade English Public School Textbook in Armenia

Our study shows that similar traditional gender roles and gender stereotypes are widely distributed in the context of the fourth grade of English textbooks too. For example, traditional gender roles, where women exclusively belong to the domestic/ private domain, and men - to the public one, can be found in a number of exercises of the fourth grade English textbook:

- Yesterday Mary helped her mother.

- Mary cleaned her room and made her bed.

- Mary helped her mother to make a cake.

- Jenny must clean her room in the afternoon.

- Mr. Brown must wash his car every week.

- Father ... the car next Sunday. Mrs. Brown ... make a cake on Saturday. Mary ... clean her room after dinner. Mother... lay the table in the kitchen.

(Gasparyan 2019:6, 18, 31)

Similar patterns can be found in another exercise, where students are provided pictures and are asked to make dialogues respectively. According to these pictures, we have the following situation: Jimmy is playing football in the yard; the father is working in the garden; Tom and Bob are playing cards in the living room; the grandfather is driving a car in the street; Mike and Tony are dancing in the living-room; etc. Here male characters are represented also in active roles. On the other hand, female characters are represented either doing some housework or in passive roles, for example, the mother is making a cake in the kitchen, Suzy is sleeping in the bedroom, the grandmother is having dinner in the dining-room, and Linda is washing her hands in the bathroom. 


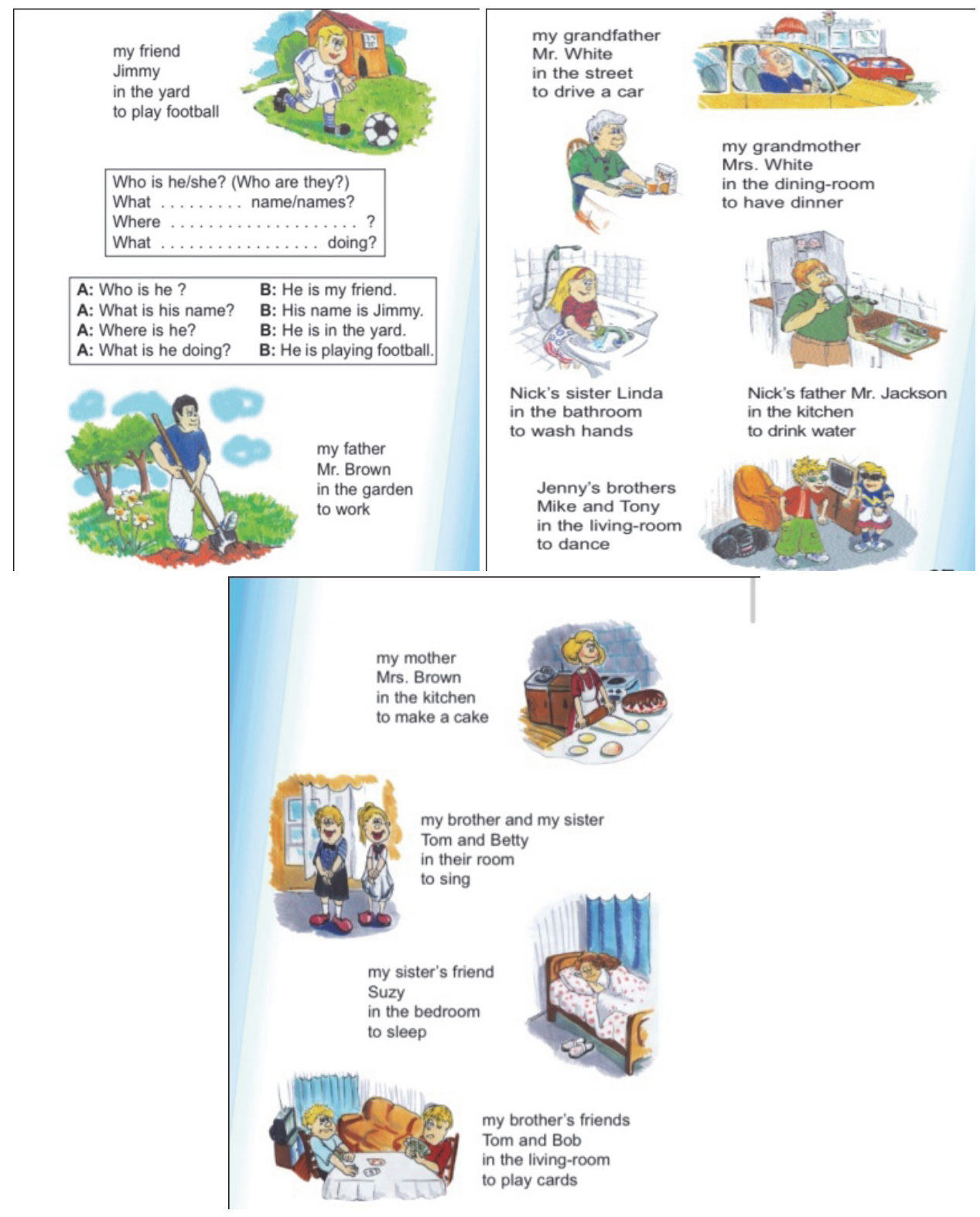

Pictures taken from English textbook, $4^{\text {th }}$ grade (Gasparyan 2019:25-27) 
This pattern continues to be observed in the context of another exercise, provided in terms of a chart.

\begin{tabular}{|l|c|c|c|c|c|}
\cline { 2 - 6 } \multicolumn{1}{c|}{} & $\begin{array}{l}\text { play } \\
\text { football }\end{array}$ & dance & $\begin{array}{c}\text { read and } \\
\text { write } \\
\text { English }\end{array}$ & $\begin{array}{c}\text { drive } \\
\text { a car }\end{array}$ & $\begin{array}{c}\text { make } \\
\text { a cake }\end{array}$ \\
\hline Tom & + & - & + & - & + \\
\hline Mary & - & + & + & - & + \\
\hline John & + & - & - & + & - \\
\hline Jane & - & - & + & - & + \\
\hline
\end{tabular}

Chart taken from English textbook, 4rd grade (Gasparyan 2019:64)

Here the requirement is to complete the sentences with can or cannot. Plus (+) should stand for can, minus (-) - for cannot. Thus, we have the following:

1) Tom can play football, read and write English, make a cake. Tom cannot dance and drive a car. 2) Mary cannot play football and drive a car, whereas she can dance, read and write English, and make a cake. 3) John can play football and drive a car, but he cannot dance, write and read English, and make a cake. 4) Jane cannot play football, dance, or drive a car, instead she can read and write English and make a cake.

(Gasparyan 2019:64)

Thus, according to this task, we get the following results: girls are good at English and making a cake and dancing, but not at playing football or driving a car. On the other hand, the boys are good at playing football, and only in one of the sentences it is provided that Tom is also able to make a cake.

The stereotypical and traditional presentation and circulation of the idea that girls are good at languages and art, whereas boys are good at STEM, continues to be circulated further in the context of other exercises of another fourth-grade textbook. For example, the following exercise requires to fill in with "to watch, to play, to write, to drink, to read": 
- Jim ... computer games every day.

- Mary ... English books.

(Apresyan 2016:7)

Other similar examples can be found in exercises 11 on page 7 , exercise 14 on page 23 , and in exercise 25 on page 95 within the same textbook.

The genderization of professions continues in the fourth-grade textbooks, too. On page 29 (author - M. Apresyan 2016), there is a text The Johnsons, where the father is presented as a doctor, and the mother - as a teacher. In the text, it is said that their son also wants to be a doctor like his father. He is good at mathematics and nature studies and knows a lot of interesting things about animals and plants.

On the next page the gendered division of professions continues to be circulated:
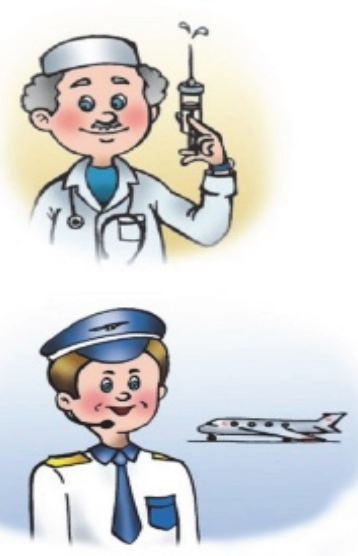

Picture taken from English textbook, $4^{\text {th }}$ grade (Apresyan 2016:31)

Like the English textbook of the $3^{\text {rd }}$ grade, in this school textbook, male characters are also presented as a pilot, driver, engineer, mathematician, which have been traditionally and stereotypically considered as male occupations. And there is only one female character depicted, who is portrayed as a teacher, 
which, as mentioned earlier, is usually considered as a typical female occupation.

In the next exercise the requirement is to make up dialogues using the pictures. The example is provided in the following way:

- -What is his/her job? -He is a doctor.

(Apresyan 2016:31)

This question concerns both sexes, and according to the question, the answer could be "she is a doctor", however it is already provided with the masculine pronoun.

Widely spread gender stereotypes on girls being tidy and good-mannered, whereas boys being untidy and rude or having a disturbing character and behavior can be found on page 93 .

5. clothes:

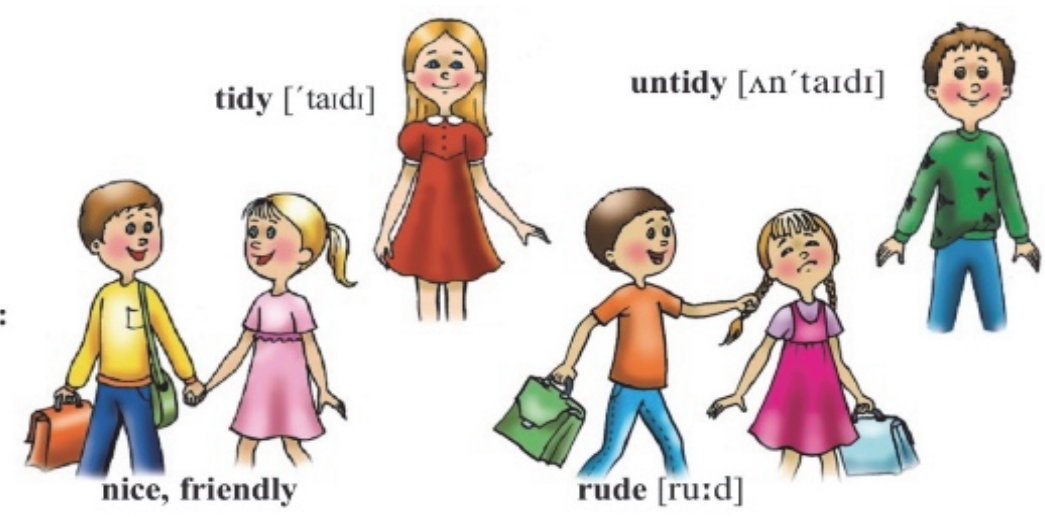

Picture taken from English textbook (Apresyan 2016:93)

The male-centered approach is obvious in this school textbook too: For example, the textbook contains informative section within each unit. These informative materials are always introduced by a male image: 


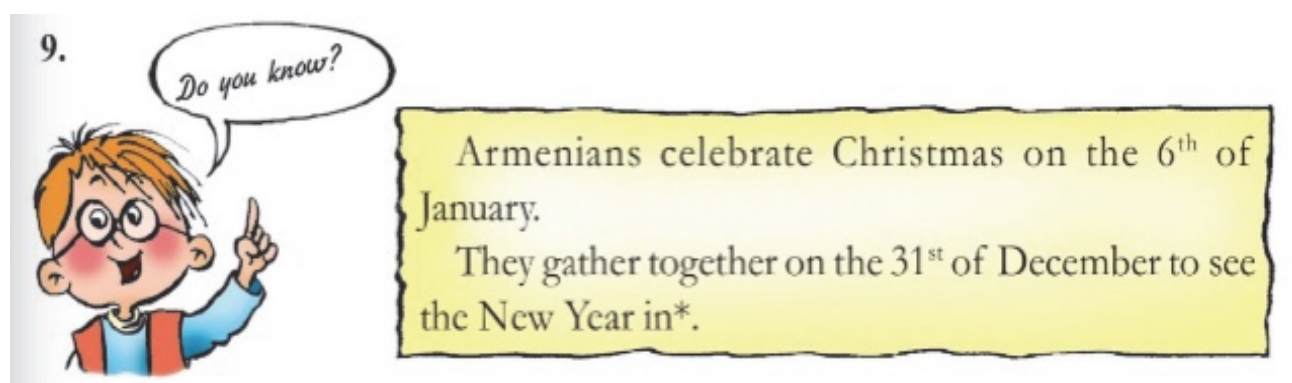

Picture taken from English textbook, $4^{\text {th }}$ grade (Apresyan 2016:55)

This male-centered approach in terms of quantity can be observed systematically throughout the whole textbook. The image proportion is the following within this textbook: $60 \%$ of pictures portray boys, while only $40 \%$ girls.

\section{Conclusion}

EFL textbooks are not only a means of teaching a foreign language but also a means of transmitting knowledge about the given culture and lingua-cultural identity. They also educate students as citizens of the country and the world, therefore during this complex and rewarding teaching-learning process gendered messages should also be taken into account.

The content analysis of the selected English primary school textbooks (Armenia) allow us to conclude that these textbooks are highly gendered in their character, i.e. they present a number of traditional gender roles as well as gender stereotypes. Moreover, they do not present these traditional gender roles and stereotypes once but circulate them systematically. Alternatively, no progressive roles and characters are depicted. These stereotypical characters and roles are introduced and presented through various texts and exercises as well as through visual images. In the context of the textbooks males are always presented as active, smart, dominant and independent characters, whereas females - as dependent, caring and passive ones.

Male characters are also overrepresented in quantity, whereas females underrepresented. Last but not least, the roles of males and females are 
unequally presented throughout the textbooks, i.e. women are not presented in their full professional capacities rather they are either depicted as wives, housewives or in learning (students) and teaching positions (teachers), the latter traditionally being considered as a "soft" and female domain/occupation, whereas men are presented as doctors, drivers, engineers, actors, scientists and pilots.

It is important to view critically what messages and roles, including gender roles and gender stereotypes are depicted in textbooks. Textbook compilers, editors and publishers should be critical to such patterns. If these traditional gender roles and gender stereotypes are reinforced and circulated over and over throughout textbooks and if they are not challenged both by teachers and students as well as by editors and publishers of textbooks, there is a risk that they will standardize and normalize or even lead to and justify certain gender discrimination and inequality patterns, which, in turn, will hinder male and female students' equal opportunities both in short-term and long-term perspectives.

\section{Notes:}

1. (1979) UN Convention on the Elimination of All Forms of Discrimination against Women. Available at:

<https://www.ohchr.org/EN/ProfessionalInterest/Pages/CEDAW.aspx>

[Accessed January 2020].

2. (2011) CoE Convention on Preventing and Combating Violence against Women and Domestic Violence. Available at:

$<$ https://rm.coe.int/168008482e > [Accessed January 2020].

3. (2013) RA law on Ensuring Equal Rights and Equal Opportunities to Women and Men. Available at:

$<$ https://www.arlis.am/DocumentView.aspx?DocID=83841> [Accessed March 2020].

4. (2019) RA 2019-2023 Gender Policy Strategy and Its Action Plan. Available at: $<$ https://www.e-draft.am/projects/1712/about> [Accessed January 2020].

5. (2020) Public Education State Standards. Available at:

$<$ https://www.e-draft.am/projects/2560/about> [Accessed January 2020]. 


\section{References:}

1. Bandura, A.; Walters R. (1963) Social Learning and Personality Development. New York: Holt, Rinehart \& Winston.

2. Crawford, M. (1995) Talking Difference: on Gender and Language. London: SAGE.

3. DeFrancisco, V.P. (2013) Gender in Communication: A Critical Introduction. Los Angeles: SAGE Publication.

4. DeFrancisco, V.P. (2007) Communicating Gender Diversity. Los Angeles: SAGE Publication.

5. Kojoyan, A. (2015) From Practice to Policy: Evaluating Language and Gender Policy in EFL Textbooks. // Language and Literature in the Contemporary Paradigm of Scientific Knowledge. / Ed. by S. Gasparyan. Vol. 7. Yerevan: Lusakn, 2016, pp. 193-204.

6. Litosseliti, L. (2006) Gender and Language: Theory and Practice. New York: Hodder Education.

7. Tsaturyan, R. (2013) Gender Roles in Armenian Elementary School Textbooks. Yerevan: OSFA.

\section{Sources of Data:}

1. Apresyan, A. (2016) English 4. Yerevan: ManMar.

2. Gasparyan, G. (2018) English 3. Yerevan: Arevik.

3. Gasparyan, G. (2019) English 4. Yerevan: Arevik.

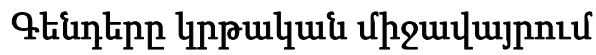 (Zujuuunuianıu huipulpponıpjui unuppulqui nu्ungh

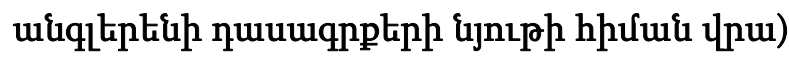

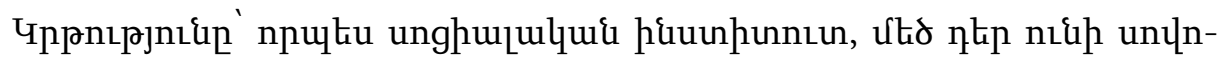

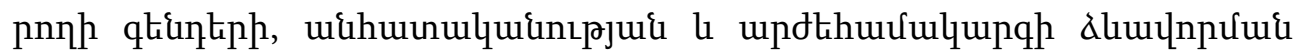

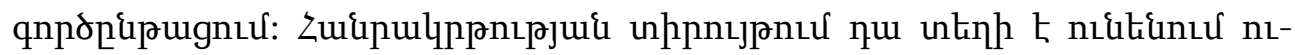

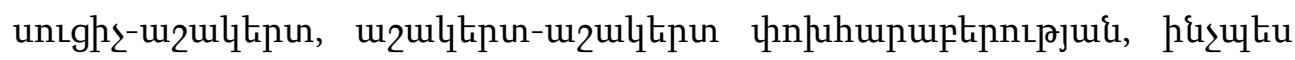

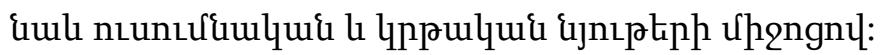




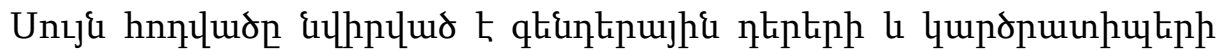

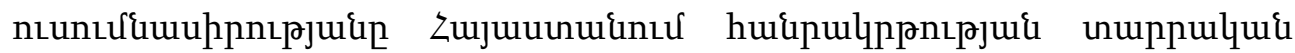

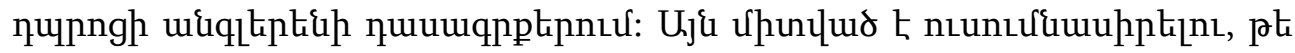

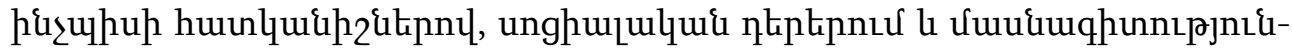

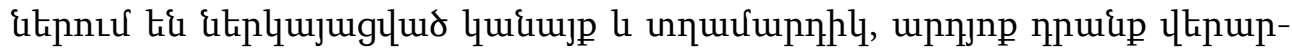

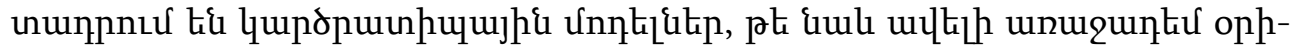
quilitip:

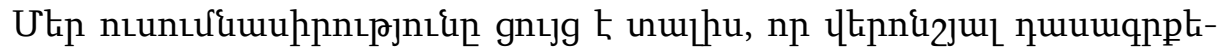

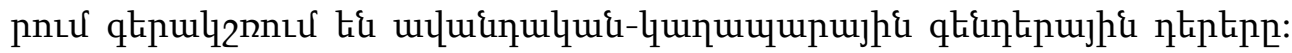

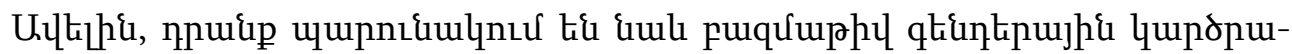

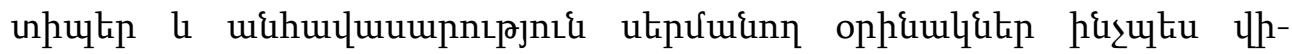

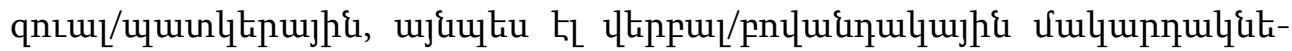

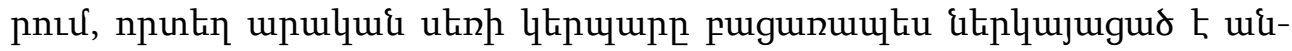

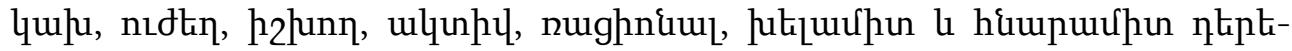

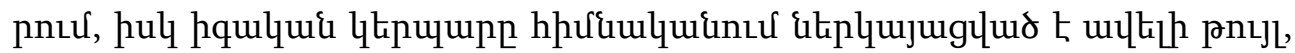

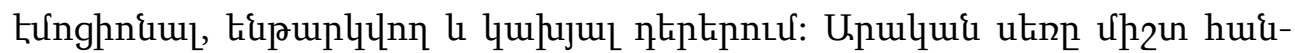

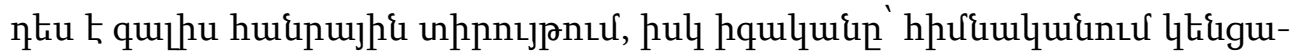

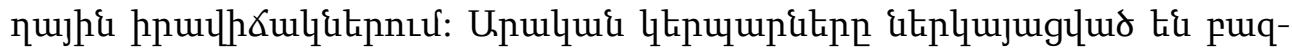

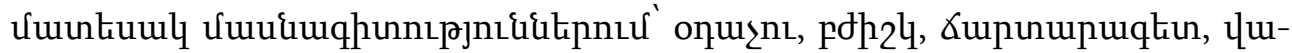

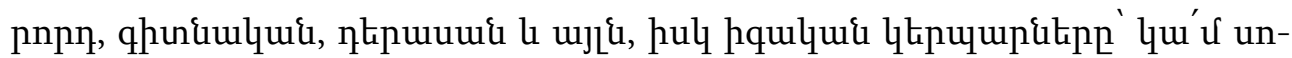

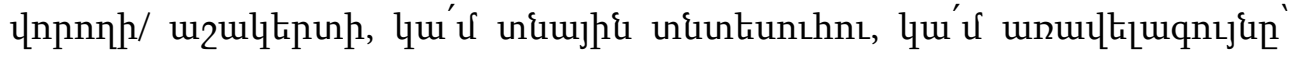

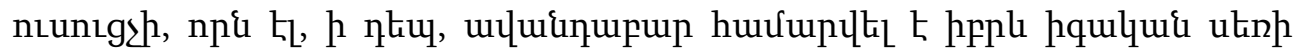

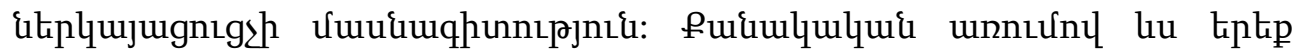

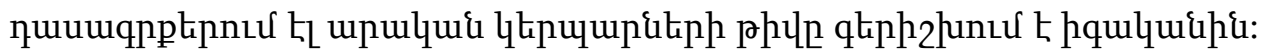

Received by the Editorial Board 24.05.2020

Recommended for publication by the reviewers 04.08 .2020

Accepted for print 05.10.2020 